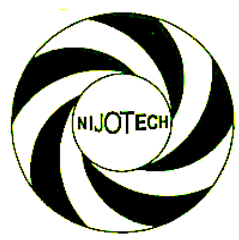

Nigerian Journal of Technology (NIJOTECH)

Vol. 37, No. 3, July 2018, pp. 626 - 632

Copyright@ Faculty of Engineering, University of Nigeria, Nsukka,

Print ISSN: 0331-8443, Electronic ISSN: 2467-8821

www.nijotech.com

http://dx.doi.org/10.4314/njt.v37i3.10

\title{
RELIABILITY ANALYSIS OF CFRP SHEAR WALLS SUBJECT TO BLAST LOADING
}

\author{
J. L. Ajimituhuo ${ }^{1}$, 0. S. Abejide ${ }^{2, *}$ and S. Mangut ${ }^{3}$ \\ 1,2,3, Department of Civil EngineERING, AhMAdu Bello University, ZARIA, Kaduna STATE. NIGERIA \\ Email addresses: ${ }^{1}$ ajimituhuo@gmail.com, ${ }^{2}$ abejideos@yahoo.com, ${ }^{3}$ mangutsamuel@gmail.com
}

\begin{abstract}
This study presents the structural reliability of CFRP shear walls subject to blast loading. The safety of a reinforced concrete shear wall, laminated with Carbon Fibre Reinforced Polymer, is modelled with a 108.9kg of Ammonium Nitrate Fuel Oil (ANFO) an explosive, with an equivalent magnitude of 87kg Trinitrotoluene (TNT). The shear performance of the laminated wall under the blast is evaluated using the First Order Reliability Method (FORM) in MATLAB environment. An increasing decline in the shear possibility of the laminated wall was observed as the standoff distance of the explosion increased, which is consistent with experimental data.
\end{abstract}

Keywords: Blast load, TNT, FORM, Shear wall. CFRP.

\section{INTRODUCTION}

Blast explosions have become more dreadfully common all over the world due to terrorism and other human activities. Apart from the obvious danger posed on lives and properties whenever blasts occur, a worrisome ambiguity seems to exist in fully reporting blast induced threats. Only agreeable threat levels are arrived at after a detailed load assessment [1]. There is therefore need for engineers to be provided with detailed experimented and simulated data in order to mitigate the alarming trend of loss during blast explosion.

On blast mitigation and resistance, many research studies have been conducted and more are still underway. A State-of-the-art review on the blast protection of unreinforced masonry walls was made [2], which proved that FRP and polyurea are the two most widely studied retrofitting techniques because of their effectiveness, lightweight, practicality of application, and cost. This was also confirmed and demonstrated [3] that FRP composites offer great benefits for the strengthening of masonry walls to resist blast loads. FRP systems have been proven to increase the out-of-plane flexure capacity of unreinforced masonry walls (URM) elements to resist a higher level of blast threat levels. Based on other researches $[4,5,6,7,8]$, it was found that FRP strengthening of Unreinforced Masonry Walls (URMs) is an effective blast explosion method, as it increases the endurance capacity of the wall structures and also prevent fragmentation. Loss of life and property damage due to high speed projectiles of the URM as a result of the blast pressure intensity can also be mitigated with the introduction of FRP.

This study however, now seeks to simulate the shear strength capacity of CFRP laminated reinforced concrete shear walls using the aforementioned trending research findings and other relevant codes as a guide. The non-linear analysis helps us to measure probabilistically its failure mode, level of response and in turn tells us how efficient our successful idea of improved shear walls in buildings will be in comparison to the conventional shear wall structures.

\section{LITERATURE REVIEW}

\subsection{Blast Phenomenon}

One of the most common scenarios in recent times around the world that imposes a nonlinear deformation on a structure is that of a blast. Blasts can cause catastrophic failure and progressive collapse to a structure. During blasts, control of deflection, crack width, vibration and other serviceability related criteria are not normally deemed essential [9].

The mechanism of a blast is such that after detonation, the ambient pressure increases almost instantaneously and promptly begins to decay, forming a nearly triangular overpressure pulse. The peak pressure is called the peak positive over pressure. It represents the pressure seen at a point in space when the shock wave is unimpeded in its motion. The duration of the positive overpressure is called the positive phase. The peak over pressure and positive phase duration determine 
the specific impulse of the blast wave. All three blast wave parameters influence the property damage and injury that the blast wave can cause [10]. Figure 1 best explains the mechanism.

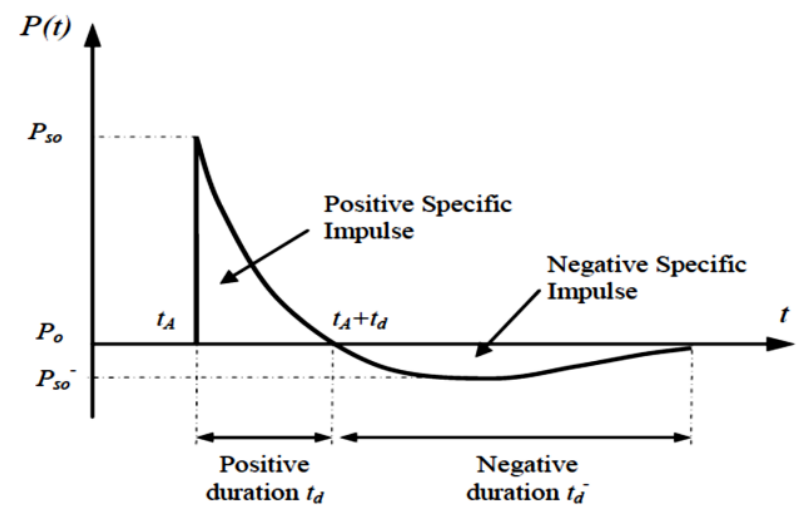

Figure 1: Relationship of blast wave pressure time history [11].

Detonation takes place at time $t=0$. After time $t_{A}$, the blast wave arrives at the point and pressure instantaneously increases from ambient pressure, $\mathrm{P}_{0}$, to peak overpressure, $\mathrm{P}_{\mathrm{so}}$, caused by the detonation. At time $t_{A}+t_{d}$, the pressure returns to ambient pressure, $\mathrm{P}_{\mathrm{o}}$, which is positive phase, and followed by negative phase, $\mathrm{P}_{\text {so. }}$.

Figure 1 expresses the simplest behavioral form of a blast wave and it is termed the Friedlander waveform. The equation for a Friedlander waveform describes the pressure of the blast wave as a function of time [12]. That is,

$$
P(t)=P_{s o}\left(e^{\left(-t / t^{x}\right)}\right)\left(1-\left(t / t^{x}\right)\right)
$$

There are common sets of equations (that is, Equations (2), (3) and (4)), which are commonly used for the calculation of blast wave from explosive charges, called the Sadovsky's formulas. Regardless of the nature of explosion, the equation converts the magnitude on trinitrotoluene (TNT) equivalent. Equations (2), (3) and (4) are the blast parameters determination for overpressure, positive phase duration and impulse [10].

$$
\begin{gathered}
\Delta P_{m}=1.02 \frac{q^{\frac{1}{3}}}{r}+4.36 \frac{q^{\frac{2}{3}}}{r^{2}}+14 \frac{q}{r^{3}} \text { (bar) } \\
\tau=1.2 \sqrt[6]{q} \sqrt{r} \quad(m s) \\
I=200 \frac{q^{\frac{2}{3}}}{r} \quad(P a)
\end{gathered}
$$

where $q$ is the explosive mass in $\mathrm{kg}$ and $r$ is the (standoff) distance in $m \Delta P_{m}$ is blast overpressure, $\tau$ is positive phase duration and $I$ is the impulse.

Equations (1) to (4) are herein subjected to reliability analysis in order to ascertain the structural safety residual in the structure after blast.

\subsection{Structural Reliability}

In daily lives, words like chances, risks, likelihood and probability are uses to indicate the uncertainty of the issue under discussion. Like-wise, structural designs are associated with uncertainties which require rational assessments. Therefore, structural reliability theory is concerned with the rational treatment of uncertainties associated with design of structures and with assessing the safety and serviceability of these structures [13]. It can also be defined as the probability that the structure under consideration has a proper performance throughout its lifetime. Reliability methods are used to estimate the probability of failure $[14,15]$.

The First Order Reliability Method (FORM) is an analytical approximation in which the reliability index is interpreted as the minimum distance from the origin to the limit state surface in standardized normal space (u-space) and the most likely failure point (design point) is searched using mathematical programming methods $[16,17]$. Because the performance function is approximated by a linear function in u-space at the design point, accuracy problems occur when the performance function is strongly nonlinear 18, 19].

In the simplest case, the performance function $g(\mathrm{X})$ is expressed as the difference between the resistance $R(\mathrm{X})$ and the demand or solicitation on the system $S(\mathrm{X})$ - that is., $g(\mathrm{X})=R(\mathrm{X})$ - $S(\mathrm{X})$. In reliability engineering analysis, $g(\mathrm{X})$ is usually expressed in terms of displacement, strain, stress, etc. The performance functions can be related to the following structural conditions [20]:

(i). Serviceability limit state: under this condition, 'failure' is related to a serviceability loss that does not imply a significant decay of structural safety.

(ii). Ultimate limit state: this condition describes the state at which structural safety is highly affected and may lead to total failure or collapse. For instance, if the reliability analysis focuses on the bending moment of a beam, the performance function is:

$$
g(X)=M_{r}(X)-M_{s}
$$

where $M_{r}(\mathrm{X})$ is the resistant bending moment of the beam that depends on $\mathrm{X}$ random variables (material strength, sectional geometry, etc.), and $M_{\mathrm{s}}$ is the soliciting bending moment. Notice that although $M_{S}$ is assumed to be deterministic in Equation (5), this variable may also be considered as a random variable. 
In the case of failure, $M_{S}>M_{r}(\mathrm{X})$, leading to the collapse of the beam.

\section{MATERIALS AND METHODS}

\subsection{Characterization of blast load (pressure)}

According to Sadovsky's formula as previously stated in Equation (2), blast pressure $\Delta P_{m}$ is a function of the mass of the bomb specimen $q$, and the standoff distance $r$. This formula works regardless of the nature of explosion and depends only on trinitrotoluene (TNT) equivalent of explosive charge.

For the purpose of this study, the blast load parameters as used [8], is characterized and simulated in the reliability analysis using MATLAB. The explosive type for the blast load case is a mixture of ammonium nitrate and fuel oil (ANFO), which is first converted to its equivalent mass in Trinitroluene (TNT). The laminated wall dimensions and properties of the wall and CFRP are also outlined. The blast load case according to Quakewrap [8] is used as:

Table 1 gives the parameter for the explosive

\section{Table 1: Parameters for the explosive}

\begin{tabular}{ll}
\hline Explosive & ANFO \\
Mass & $108.9 \mathrm{~kg}$ \\
TNT equivalence factor & 0.88 \\
TNT Equivalent mass & $87.9 \mathrm{~kg}$ \\
Explosive charge & $3717 \mathrm{~kJ} / \mathrm{kg}$ \\
Stand-off distance & $9.14 \mathrm{~m}$ \\
\hline
\end{tabular}

(b) Calculations using Sadovsky's Formula

(i). $\begin{aligned} \Delta P_{m} & =1.02 \frac{(87.9)^{\frac{1}{3}}}{9.14}+3.9 \frac{(87.9)^{\frac{2}{3}}}{9.14^{2}}+13 \frac{(87.9)}{9.14^{3}} \\ \Delta P_{m} & =3.1397 \mathrm{bar}=314 \mathrm{kN} / \mathrm{m}^{2}\end{aligned}$

(ii). $\quad \tau=1.2 \sqrt[6]{87.9} \sqrt{9.14}=0.01 \mathrm{sec}($ approx...)

(iii). $\quad I=200 \frac{87.9^{\frac{2}{3}}}{9.14}=432.6 \mathrm{~N} / \mathrm{m}^{2}$

Table 2 shows the material properties of the CFRP laminated reinforced concrete shear wall.

\subsection{Load Factorization for the Shear Wall [21]}

The factored load combination for a reinforced concrete wall is given [21] in Equation (6), where D is dead load, $\mathrm{H}$ is lateral earth pressure (for retaining walls) and L is live load.

$$
\varphi U \geq 1.2 D+1.6 H+1.6 L
$$

Considering the scope of shear capacity for this study, the strength design for reinforced concrete shear wall can be derived from Equation (6) as;

$\varphi U \geq 1.2 D+1.6 L$ (no lateral earth pressure) (7) where, $U$ is the shear strength capacity of the FRP laminated shear wall as given in Equation (8) [8, 22 24].

$$
\begin{aligned}
U=V=v_{c}+v_{s} & +v_{f} \\
& =\left(1+\frac{N_{u}}{14 A_{g}}\right)\left(\frac{\sqrt{f^{\prime}}}{6}\right)+\frac{A_{v} f_{y} d}{s_{2} A_{s}} \\
& +0.8 E_{f} \varepsilon_{f} \rho_{f} \quad(M P a)
\end{aligned}
$$

where, $\mathrm{N}_{\mathrm{u}}$ is the axial compression force, $\mathrm{A}_{\mathrm{g}}$ the area of the cross section, $A_{y}$ is the area of horizontal shear reinforcement within a vertical distance, $S_{2}$ and horizontal distance, $d, \mathrm{~A}_{s}$ the area of shear surface, $f_{y}$ is the characteristic strength of the steel reinforcement, $E_{f}$ is the Young's modulus of fibre, $\varepsilon_{\mathrm{f}}$ is effective FRP strain at failure, which is calculated as 0.0025 (FRP rupture) and 0.002 (FRP de-bonding), $\rho_{f}$ is FRP shear reinforcement ratio, which is $2 \frac{t_{f}}{b_{w}}$ for continuously bonded shear reinforcement with thickness $t_{f}$. $t_{f}$ is the thickness of the fibre, $D$ is the length of flange wall, $b_{w}$ is the thickness of the flange and $\varphi$ is the strength reduction factor ( 0.9 for bending and 0.75 for shear).

The calculation of the performance function is performed for discrete combination of basic variables considering the shear failure of the reinforced concrete shear wall with CFRP laminate as external reinforcement in accordance with the code [21] from Equation (8) as:

$$
\begin{array}{r}
G(x)=0.75 \times\left[\left(1+\frac{N_{u}}{14 A_{g}}\right)\left(\frac{\sqrt{f_{c}^{\prime}}}{6}\right)+\frac{A_{y} f_{y} d}{s_{2} A_{s}}\right. \\
\left.+0.8 E_{f} \varepsilon_{f} \rho_{f}\right]-[1.2 D+1.6 L]
\end{array}
$$

In Equation (9), dead to live load ratio may be expressed as ALPHA, axial compressive force; $\mathrm{N}_{\mathrm{u}}$, as a function of the blast overpressure and blast surface, while the shear reinforcement ratio, $\rho_{f}$, as a function of the CFRP laminate thickness and the depth.

Table 2: Material properties of CFRP laminated reinforced concrete shear wall.

\begin{tabular}{cccccc}
\hline Materials & $\begin{array}{c}\text { Compressive } \\
\text { strength }\left(\mathrm{N} / \mathrm{mm}^{2}\right)\end{array}$ & $\begin{array}{c}\text { Yield strength } \\
\left(\mathrm{N} / \mathrm{mm}^{2}\right)\end{array}$ & $\begin{array}{c}\text { Young Modulus } \\
\left(\mathrm{N} / \mathrm{mm}^{2}\right)\end{array}$ & $\begin{array}{c}\text { Density } \\
\left(\mathrm{N} / \mathrm{mm}^{3}\right)\end{array}$ & Poisson's ratio \\
\hline Concrete & 30 & - & 31 & 2400 & 0.2 \\
Steel & - & 410 & $210 \mathrm{E}+09$ & 7880 & 0.33
\end{tabular}


Thus, Equation (9) can be re-written as:

$$
\begin{aligned}
G(x)=0.75 \times[ & \left(1+\frac{\Delta P_{m} * A_{s}}{14 A_{g}}\right)\left(\frac{\sqrt{f_{c}^{\prime}}}{6}\right)+\frac{A_{y} f_{y} d}{s_{2} A_{s}} \\
& \left.+0.8 E_{f} \varepsilon_{f} 2 \frac{t_{f}}{b_{w}}\right] \\
& -[1.2 A L P H A+1.6]
\end{aligned}
$$

Equation (10) is the MATLAB reliability analysis (FORM) to check the shear performance of the laminated shear wall as the standoff distance and laminate thickness varies independently. The structural safety indices and corresponding probability of failures were obtained.

Table 3 shows calculations that further explain the process in the MATLAB analysis.

\section{RESULTS AND DISCUSSION}

The results obtained and discussion arising are therefore are presented below in Table 4 and Figures 2 and 3.

Table 3: Stochastic models of the shear performance function of CFRP-laminated reinforced concrete shear walls

\begin{tabular}{|c|c|c|c|}
\hline $\begin{array}{c}\text { Laminate } \\
\text { thickness } \mathrm{mm}\end{array}$ & $\begin{array}{c}\text { Dead load } \\
G_{k}\end{array}$ & $\begin{array}{c}\text { ALPHA }= \\
\mathrm{G}_{\mathrm{k}} / \mathrm{Q}_{\mathrm{k}}\end{array}$ & BETA \\
\hline \multicolumn{4}{|c|}{ At $5 \mathrm{~m}$ stand-off, $\mathrm{Q}_{\mathrm{k}}=6389.820 \mathrm{kN}$} \\
\hline 10 & 22275 & 0.0035 & 1.2383 \\
\hline 15 & 22612.5 & 0.0035 & 1.2383 \\
\hline 20 & 22950 & 0.0036 & 1.2383 \\
\hline 25 & 23287.5 & 0.0036 & 1.2383 \\
\hline 30 & 23625 & 0.0037 & 1.2383 \\
\hline 35 & 23962 & 0.0038 & 1.2383 \\
\hline \multicolumn{4}{|c|}{ At $9.14 \mathrm{~m}$ stand-off, $\mathrm{Q}_{\mathrm{k}}=1412.865 \mathrm{kN}$} \\
\hline 10 & 22275 & 0.016 & 1.2384 \\
\hline 15 & 22612.5 & 0.016 & 1.2384 \\
\hline 20 & 22950 & 0.016 & 1.2384 \\
\hline 25 & 23287.5 & 0.016 & 1.2384 \\
\hline 30 & 23625 & 0.017 & 1.2384 \\
\hline 35 & 23962 & 0.017 & 1.2384 \\
\hline \multicolumn{4}{|c|}{ At $10 \mathrm{~m}$ stand-off, $\mathrm{Q}_{\mathrm{k}}=1145.700 \mathrm{kN}$} \\
\hline 10 & 22275 & 0.019 & 1.2385 \\
\hline 15 & 22612.5 & 0.02 & 1.2385 \\
\hline 20 & 22950 & 0.02 & 1.2385 \\
\hline 25 & 23287.5 & 0.02 & 1.2385 \\
\hline 30 & 23625 & 0.02 & 1.2385 \\
\hline 35 & 23962 & 0.021 & 1.2385 \\
\hline \multicolumn{4}{|c|}{ At $15 \mathrm{~m}$ stand -off, $\mathrm{Q}_{\mathrm{k}}=472.500 \mathrm{kN}$} \\
\hline 10 & 22275 & 0.047 & 1.2389 \\
\hline 15 & 22612.5 & 0.048 & 1.2389 \\
\hline 20 & 22950 & 0.049 & 1.2389 \\
\hline 25 & 23287.5 & 0.049 & 1.2389 \\
\hline 30 & 23625 & 0.051 & 1.2389 \\
\hline 35 & 23962 & 0.051 & 1.2389 \\
\hline
\end{tabular}

\begin{tabular}{lclllll}
\hline S/N & VARIABLES & MEANING & DISTIBUTION & MEAN & COVARIANCE & SD \\
\hline 1 & $\Delta P_{m}$ & Peak over-pressure & Lognormal & $280635 \mathrm{~N} / \mathrm{m}^{2}$ & 1.58 & 442602.757 \\
2 & $A_{s}$ & Area of pressured surface & Normal & $4.5 \mathrm{~m}^{2}$ & - & - \\
3 & $t_{f}$ & CFRP laminate thickness & Normal & $20 \mathrm{~mm}$ & 0.5 & 10 \\
4 & $b_{w}$ & RC wall thickness & Normal & $200 \mathrm{~mm}$ & 0.5 & 100 \\
\hline
\end{tabular}

Table 4: Summary of the reliability analysis

\begin{tabular}{|c|c|c|c|}
\hline 10 & 22275 & 0.083 & 1.2394 \\
\hline 15 & 22612.5 & 0.084 & 1.2394 \\
\hline 20 & 22950 & 0.086 & 1.2394 \\
\hline 25 & 23287.5 & 0.087 & 1.2394 \\
\hline 30 & 23625 & 0.088 & 1.2394 \\
\hline 35 & 23962 & 0.089 & 1.2394 \\
\hline \multicolumn{4}{|c|}{ At $25 \mathrm{~m}$ stand-off, $\mathrm{Q}_{\mathrm{k}}=179.145 \mathrm{kN}$} \\
\hline 10 & 22275 & 0.124 & 1.240 \\
\hline 15 & 22612.5 & 0.126 & 1.240 \\
\hline 20 & 22950 & 0.128 & 1.240 \\
\hline 25 & 23287.5 & 0.130 & 1.240 \\
\hline 30 & 23625 & 0.132 & 1.240 \\
\hline 35 & 23962 & 0.134 & 1.240 \\
\hline \multicolumn{4}{|c|}{ At $30 \mathrm{~m}$ stand-off, $\mathrm{Q}_{\mathrm{k}}=131.670 \mathrm{kN}$} \\
\hline 10 & 22275 & 0.167 & 1.2406 \\
\hline 15 & 22612.5 & 0.172 & 1.2406 \\
\hline 20 & 22950 & 0.174 & 1.2406 \\
\hline 25 & 23287.5 & 0.177 & 1.2406 \\
\hline 30 & 23625 & 0.179 & 1.2406 \\
\hline 35 & 23962 & 0.182 & 1.2406 \\
\hline \multicolumn{4}{|c|}{ At $35 \mathrm{~m}$ Stand-off, $\mathrm{Q}_{\mathrm{k}}=102.916 \mathrm{kN}$} \\
\hline 10 & 22275 & 0.216 & 1.2413 \\
\hline 15 & 22612.5 & 0.220 & 1.2413 \\
\hline 20 & 22950 & 0.223 & 1.2413 \\
\hline 25 & 23287.5 & 0.226 & 1.2413 \\
\hline 30 & 23625 & 0.230 & 1.2413 \\
\hline
\end{tabular}

\begin{tabular}{c|c|c|c}
\hline $\begin{array}{c}\text { Laminate } \\
\text { thickness } \mathrm{mm}\end{array}$ & $\begin{array}{c}\text { Dead load } \\
\mathrm{G}_{\mathrm{k}}\end{array}$ & $\begin{array}{c}\text { ALPHA }= \\
\mathrm{G}_{\mathrm{k}} / \mathrm{Q}_{\mathrm{k}}\end{array}$ & BETA \\
\hline
\end{tabular}

At $20 \mathrm{~m}$ stand-off, $\mathrm{Q}_{\mathrm{k}}=268.245 \mathrm{kN}$ 


\begin{tabular}{c|c|c|c}
\hline $\begin{array}{c}\text { Laminate } \\
\text { thickness } \mathrm{mm}\end{array}$ & $\begin{array}{c}\text { Dead load } \\
\mathrm{G}_{\mathrm{k}}\end{array}$ & $\begin{array}{c}\text { ALPHA }= \\
\mathrm{G}_{\mathrm{k}} / \mathrm{Q}_{\mathrm{k}}\end{array}$ & BETA \\
\hline 35 & 23962 & 0.233 & 1.2413 \\
\hline
\end{tabular}

The safety indices plots for the shear failure criterion of the CFRP laminated reinforced concrete shear wall are also presented in Figures 2 and 3 respectively.

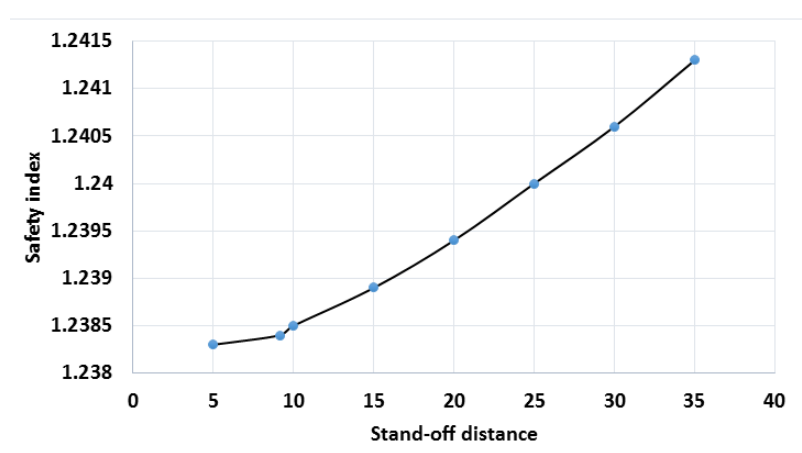

Figure 2: Relationship of structural safety to stand-off distances.

Figure 2 shows the effect of varying the stand-off distance of the explosion from $5 m-35 m$ on the safety of the laminated shear wall (in shear). A linear relationship is observed as the structural safety of the wall increases with increase in stand-off distance of the blast.

Figure 3 presents multiple relationships of the structural safety indices to laminate thicknesses at various stand-off distances. This implies that at every stand-off distance (from $5-35 \mathrm{~m}$ ), the thickness of the laminate is varied and then the resistance of the wall to shear failure observed.

The multiple relationship is necessary because ratio of dead load to live load varies each time another layer of thickness is added. This however did not seem to significantly affect the structural safety indices within a stand-off range; hence the straight line relationships. This reflects that increase in the laminate thickness does not necessarily affect the shear deformation of the composite wall, which could have been because of the grade and material property of CFRP laminate (that is graphite lamina) chosen for the study. It can be recalled that the expression of shear capacity given in Equation (8) that the Young's modulus of the CFRP (due to grade) is far less than the rest two components (concrete and steel) of the entire composite. This however explains the insignificance in the safety indices of the structure during the run of the reliability analysis, while choosing laminate thickness as a variable.

\section{CONCLUSION AND RECOMMENDATION}

This study focuses exclusively on the reliability analysis of CFRP laminated reinforced concrete shear wall. The analysis also shows that the intrinsic structural safety of the shear capacity of laminated shear wall increases as the explosion blasts farther away from the wall. It however reveals that increases in laminate thickness for shear resistant design under blast loading is dependent on the grade of laminate used and that laminates with higher Young's modulus will effectively improve the structural safety of the shear walls.

For further experimental purposes, studies on how to achieve a high performing composite structure when combining CFRP and concrete is recommended. These would cater for cases of premature de-bonding which is a known failure criterion in combining composites with reinforced concrete as one entity. 


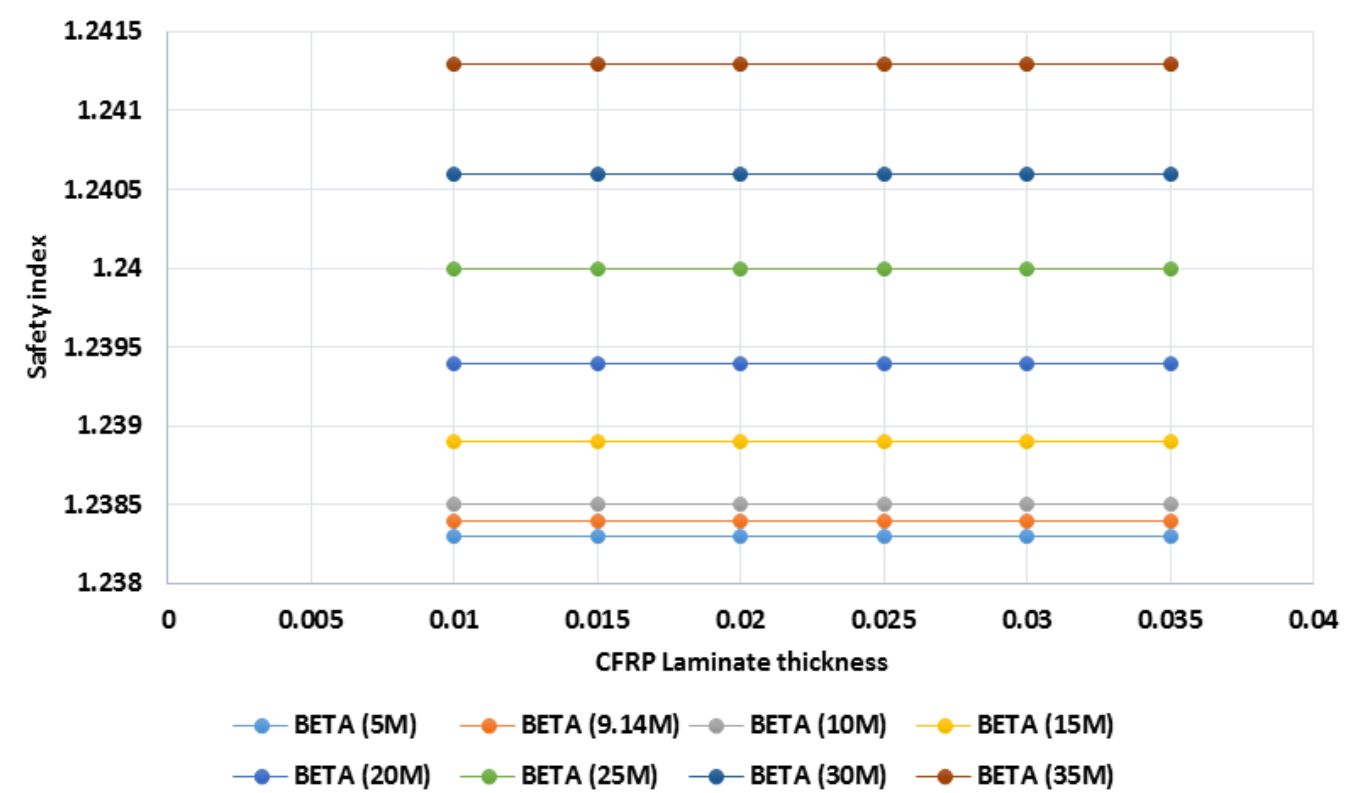

Figure 3: Relationship of structural safety to CFRP laminate thickness at various stand-off distances.

\section{REFERENCES}

[1] Manmohan D. G. and Vasant M. (2014) "BlastResistant Design of Structures" Researchgate: Practice Periodical on Structural Design and Construction May 2014. www.researchgate.net/publication/262374833

[2] Lantz, L., Joshua, M., Cook, W. and Claudia, M. D. W. (2016) "Blast Protection of Unreinforced Masonry Walls:A State-of-the-Art Review" Hindawi Publishing Corporation Advances in Civil Engineering Volume 2016.

[3] Myers, J. J., Abdeldjelil B., Khaled A. and ElDomiaty (2004) "Blast Resistance of FRP Retrofitted Un-Reinforced Masonry (URM) Walls With and Without Arching Action" The Masonry Society Journal, The Masonry Society, Sep 2004.

[4] Bazan, M. L. and Charles J. (2010) "Protection Engineering Consultants, 4203 Gardendale, Suite C112, San Antonio, TX 78229

[5] Buchan, P.A. and Chen, J.F. "Blast resistance of FRP composites and polymer strengthened concrete and masonry structures - A state-of-the-art review" Composites Part B: Engineering Vol. 38, No. 5-6, 2007, p. 509-522.

[6] Verma, S., Choudhury, M. and Saha, P. "Blast Resistant Design of Structure" IJRET: International Journal of Research in Engineering and Technology, 5(1), pp 254-261. 2016.

[7] Carney, P. and Myers, J. J. (2005) "Out-of-Plane Static and Blast Resistance of Unreinforced Masonry Wall Connections Strengthened with FRP" American Concrete Institute, Special Publication Vol. 230, 229-248
[8] Ehsani M. and Pena C. (2009) "Blast Loading Retrofit of Unreinforced Masonry Walls With Carbon Fibre Reinforced Polymer (CFRP) Fabrics" Structure Magazine 2009. www.structuremag.org

[9] Razaqpur, G. A., Tolba, A. and Contestabile, E. (2006). "blast loading response of reinforced concrete panels reinforced with externally bonded GFRP laminates". Science Direct, Composites: Part B 38 (2007) 535-546

[10] Bajic, Z. Bogdanov, J. and Jeremic, R (2009). "Blast effects evaluation using TNT" equivalent.Military Academy, PavlaJurisica Sturma Belgrade SERBIA. Scientific Technical Review, Vol.LIX, No.3-4, 2009

[11] Mohammed A. L., Rafika N. R., Norazman M. N., Ariffin I., Muhammad A. Y., Ng C. P. (2014): "Simulation of Reinforced Concrete Blast Wall Subjected to Air Blast Loading" Journal of Asian Scientific Research, 2014, 4(9): 522-533

[12] Dewey J. M. (2010): "The Shape of the Blast Wave: Studies of the Friedlander Equation". Presented at the 21st International Symposium on Military Aspects of Blast and Shock, Israel 2010.

[13] Mansour, A. E. (1989). An Introduction to Structural Reliability Theory. Mansour Engineering Inc Berkeley Ca.

[14] Sørensen, J. D. (2004). Notes in Structural Reliability Theory and Risk Analysis. Institute of Building Technology and Structural Engineering. Aalborg University. Denmark.

[15] Thoft-Christensen, P., M.J., Barker, (1982) "Structural Reliability Theory and its Applications" Springer-Verlag Berlin Heidelberg, $1^{\text {st }}$ Edition 1982. 
[16] Hasofer AM, Lind NC. Exact and invariant secondmoment code format. J Engrg Mech Division, ASCE1974;100 (1):111 - 121.

[17] Shinozuka M. Basic analysis of structural safety. J of Struct Engrg, ASCE 1983;109 (3):721 -140.

[18] Fiessler B Neumann H-J, Rackwitz R. Quadratic limit states in structural reliability. J Engrg Mech, ASCE 1979;105 (4):661 - 676.

[19] Tichy M. First-order third-moment reliability method. Structural Safety 1994;16:189 - 200.

[20] Bastidas-Arteaga, E., and Soubra, A. H. (2014). Reliability Analysis Methods. John Wiley and Sons, New York.

[21] ACI 318, (2005). Building code requirements for structural concrete and commentary. ACI 318-05, American Concrete Institute, Detroit.
[22] Li, Z. J. T., Balendra, K.H.T., and Kong K.H. (2005). Finite element modelling of cyclic behaviour of shear wall structure retrofitted using GFRP. American Concrete Institute, Special publication. Vol. 230 pp 1305-1324.

[23] Galal, K and El-Sokkary H. (2012). "Cyclic Tests on FRP-Retrofitted RC Shear Wall Panels". The $15^{\text {th }}$ World Conference on Earthquake Engineering (WCEE), Lisboa (2012).

[24] Sejal, B. (2014). "Optimization of a Multi-StoreyBuilding by Optimum Positioning of Shear Wall". IJRET: International Journal of Research in Engineering and Technology, Volume: 02 Issue: 04| Jul-2015. 